\title{
Supramolecular Encapsulation of Neutral Diazoacetate Esters and Catalyzed 1,3-Dipolar Cycloaddition Reaction by a Self-Assembled Hexameric Capsule
}

\author{
Giorgio La Sorella, Laura Sperni, Giorgio Strukul, and Alessandro Scarso ${ }^{*[a]}$
}

\begin{abstract}
Diazoacetate esters proved to be suitable neutral guests for the self-assembled resorcin[4]arene hexameric capsule. The hydrogen-bonded supramolecular host catalyzed the 1,3-dipolar cycloaddition reaction between diazoacetate esters and electron-poor alkenes such as acrolein, acrylonitrile, predominantly trans-crotonaldehyde, trans-2-hexenal, methyl, and butyl acrylate, which led to the corresponding 4,5-dihydro- $1 \mathrm{H}$-pyrazole derivatives. The cycloaddition reaction occurred within the cavity of the capsule. In fact, substantial inhibition of the cata-
\end{abstract}

lytic activity was observed by employing tetraethylammonium tetrafluoroborate characterized by greater affinity for the hexameric capsule as a competitive guest; its presence inhibited access of the substrates. The 1,3-dipolar cycloaddition reaction between diazoacetate esters and acrylate esters of different lengths showed a significant degree of substrate selectivity owing to the encapsulation of the reagents before the cycloaddition reaction.

\section{Introduction}

The constant inspiration from nature in the development of more efficient and selective artificial enzymes has spurred the implementation of supramolecular interactions in homogeneous catalysis. Enzymes are extremely complex macromolecular catalysts in which the substrate is surrounded by the peptide chain in proximity to the active site. The mimic of this high surface interaction in homogeneous catalysts poses the problem of complex and tedious synthesis of new catalysts endowed with supramolecular features. A possible approach consists in the employment of self-assembling artificial supramolecular catalysts for which the functionalities installed in the subunits allow the formation of sufficiently large cavities featuring substrate recognition as well as catalytic activity. ${ }^{[1-3]}$ Hence, supramolecular catalysis is growing as a new cross discipline that points at implementing weak intermolecular forces ${ }^{[4]}$ in artificial catalysts to achieve high activity and product and substrate selectivity. ${ }^{[5]}$ An important differentiation exists between supramolecular catalysts operating in water and those operating in organic media. In the former medium, a wide range of host structures with catalytic performance have been developed in recent times, in particular calixarene-like and capsulelike unimolecular or self-assembled supramolecular catalysts. ${ }^{[3,5]}$ The most important driving force favoring reactivity in water is the hydrophobic effect that promotes encapsulation of the

[a] G. La Sorella, L. Sperni, Prof. Dr. G. Strukul, Dr. A. Scarso

Dipartimento di Scienze Molecolari e Nanosistemi

Università Ca' Foscari di Venezia

Calle Larga S. Marta 2137, 30123, Venezia (Italy)

Fax: (+ 39) 0412348517

E-mail:alesca@unive.it

Supporting Information for this article is available on the WWW under http://dx.doi.org/10.1002/cctc.201402631. substrates and eventually their reaction. In organic media this cannot occur and other weak intermolecular forces as well as size effects and packing coefficient effects ${ }^{[6]}$ are dominant to promote catalysis within confined spaces.

Among possible host structures, resorcin[4]arene $1^{[7]}$ with long alkyl chains is an easily prepared building block that in apolar, water-saturated solvents such as chloroform and benzene spontaneously self-assembles above micromolar concentrations to form hexameric capsule $\mathbf{1}_{6} \cdot 8 \mathrm{H}_{2} \mathrm{O}$ held together by 60 hydrogen bonds (Scheme 1). The assembly presents a cavity with a volume of approximately $1375 \AA^{3}$ that can accommodate from six to eight chloroform or benzene solvent molecules. ${ }^{[8]}$ Resorcin[4]arene is a beautiful supramolecular nanometric object that has been studied for a long time for its ability to host species through two distinctive processes. Cationic guests such as organic ammonium and phosphonium ions ${ }^{[9]}$ or metal species ${ }^{[10]}$ can be encapsulated and stabilized through cation $-\pi^{[11]}$ interactions with the electron-rich concave aromatic internal surfaces of the cavity. In addition, the capsule binds species such as carboxylic acids, amino acids, ${ }^{[12]}$ and alcohols, ${ }^{[13]}$ which are often used in large molar excess.

In recent years, the hexameric capsule, thanks to its large cavity, has started to be employed as a nanometric supramolecular catalyst to steer activity and selectivity. In particular, the capsule has been shown to act as both an inhibitor encapsulating a photo-oxidation catalyst ${ }^{[14]}$ and a stable solvation sphere to influence product ${ }^{[15]}$ as well as substrate ${ }^{[16]}$ selectivity in alkyne hydration reactions catalyzed by $\mathrm{Au}^{\prime}$ complexes. Zhang and Tiefenbacher demonstrated that the seam of the hydrogen bonds of the hexamer stabilized the deprotonation of $\mathbf{1}_{6} \cdot 8 \mathrm{H}_{2} \mathrm{O}$ that acted as a reasonably strong Brønsted acid $\left(\mathrm{p} K_{\mathrm{a}} \approx 5.5-6\right)$ and promoted substrate-selective diethyl acetal hydrolysis as well as the Wittig reaction. ${ }^{[17]}$ Recently, we dis- 
6

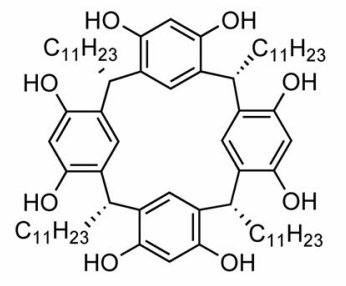

1

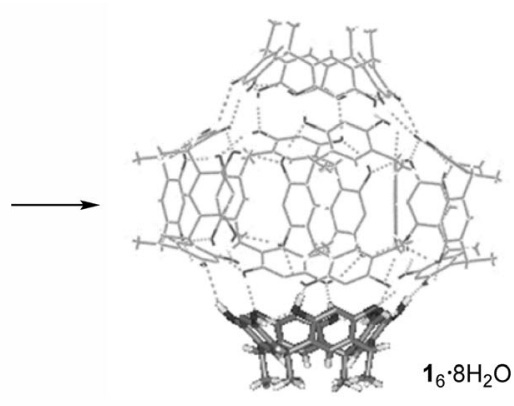

(3a-f

\section{Results and Discussion}

\section{Encapsulation of diazoacetates within $1_{6} \cdot 8 \mathrm{H}_{2} \mathrm{O}$}

Encapsulation of the neutral guest ethyl diazoacetate ( 2 a) was observed by its simple addition (10 equiv.) to a solution of self-assembled capsule $\mathbf{1}_{6} \cdot 8 \mathrm{H}_{2} \mathrm{O}$ in water-saturated $\mathrm{CDCl}_{3}$.

New upfield-shifted broad resonances were observed in the ${ }^{1} \mathrm{H}$ NMR spectrum in the $\delta=-0.86$ to $-1.06 \mathrm{ppm}$ range, and this corresponded to an upfield shift of $\Delta \delta \approx-2.1 \mathrm{ppm}$ (Figure 1 B). The shielding effect provided by the internal surface of the capsule to the terminal ethyl ester moiety of the substrate confirmed the uptake of the diazoacetate by the capsule. The same results were observed with tert-butyl diazoacetate ( $\mathbf{2} \mathbf{b})$ and benzyl diazoacetate (2c). The former showed a pair of major, slightly broad singlet resonances at $\delta=-0.50$ and $-0.52 \mathrm{ppm}$, which corresponded to an upfield shift of $\Delta \delta \approx-2.0 \mathrm{ppm}$ (Figure 1D). The latter showed several partially overlapped resonances of the encapsulated substrates at $\delta \approx 6.4 \mathrm{ppm}$ for the aromatic moiety and at $\delta=3.8 \mathrm{ppm}$ for the benzyl moiety (Figure 1 F).

The encapsulation of diazoacetate neutral guests within $\mathbf{1}_{6} \cdot 8 \mathrm{H}_{2} \mathrm{O}$ can be rationalized on the basis of recent findings by our group. It was disclosed that isonitrile molecules characterized by carbene-like character $^{[19]}$ are efficiently encapsulated within $1_{6} \cdot 8 \mathrm{H}_{2} \mathrm{O}^{[18]}$ thanks to the stabilization imparted by the electron-rich internal surface of the capsule. Therefore, extension to other carbene-like neutral molecules such as diazoacetate esters was expected to occur. In fact, diazoacetate esters are well-known re-

closed that isonitriles, thanks to their carbene-like character, are a new class of efficiently encapsulated neutral guests for the hexamer. Moreover, as a consequence of encapsulation, isonitriles are smoothly hydrated to the corresponding formamides within the capsule. ${ }^{[18]}$ This recent finding prompted us to explore other neutral carbene-like molecules as guests to benefit from for the catalytic effect of the capsule in promoting bimolecular reactions.

In the present contribution, we report the efficient encapsulation of diazoacetate esters $\mathbf{2} \mathbf{a}-\mathbf{c}$ as neutral substrate molecules and their 1,3-dipolar cycloaddition reactions with electron-poor alkenes $\mathbf{3}$ a-f selectively leading to 4,5-dihydro- $1 \mathrm{H}$ pyrazole derivatives $\mathbf{4}$ aa-cf (Scheme 1).

The reaction is likely to occur within the cavity of the capsule. In fact, in the presence of tetraethylammonium tetrafluoroborate (5a) as a competitive guest, substantial inhibition of the catalytic activity was observed. The reaction between diazoacetate esters $\mathbf{2} \mathbf{a}-\mathbf{c}$ and electron-poor alkenes $\mathbf{3} \mathbf{a}-\mathbf{f}$ showed a significant degree of substrate selectivity owing to the co-encapsulation of the reagents before the cycloaddition reaction. agents that are characterized by remarkable chemical reactivity as carbene precursors simply by loss of dinitrogen. ${ }^{[2,21]}$

The different affinity of substrates $\mathbf{2} \mathbf{a}-\mathbf{c}$ for the capsule were measured by integrating the upfield-shifted resonances of the encapsulated diazoacetate esters in different molar ratios with respect to the capsule. With 10 equivalents of $\mathbf{2} \mathbf{a}$ and $\mathbf{2} \mathbf{b}$ with respect to the capsule, quantitative formation of one-to-one host-guest adducts was observed, whereas for $2 \mathrm{c}$ the same investigation was not possible because of overlap of the resonances of encapsulated diazoacetate $2 \mathrm{c}$ and those of $\mathbf{1}_{6} \cdot 8 \mathrm{H}_{2} \mathrm{O}$. With larger amounts of $\mathbf{2} \mathbf{a}$ and $\mathbf{2} \mathbf{b}$, it is likely that more than one molecule of diazoacetate per capsule could be accommodated. In fact, in the presence of 20 equivalents of $2 a$, an average of 1.6 molecules of this substrate was encapsulated within the capsule, whereas for $\mathbf{2} \mathbf{b}$, and average of 1.8 molecules was encapsulated, which confirmed the slightly better affinity of the tert-butyl-substituted diazoacetate substrate with respect to the ethyl counterpart probably because of better $\mathrm{CH}-\pi$ interactions. Substrates $\mathbf{2} \mathbf{a}-\mathbf{c}$ were shown to be stable in watersaturated $\mathrm{CDCl}_{3}$ both in the presence and in the absence of $1_{6} \cdot 8 \mathrm{H}_{2} \mathrm{O}$ even at $50^{\circ} \mathrm{C}$ for more than $20 \mathrm{~h}$ without substantial formation of typical decomposition products such as fumarate 

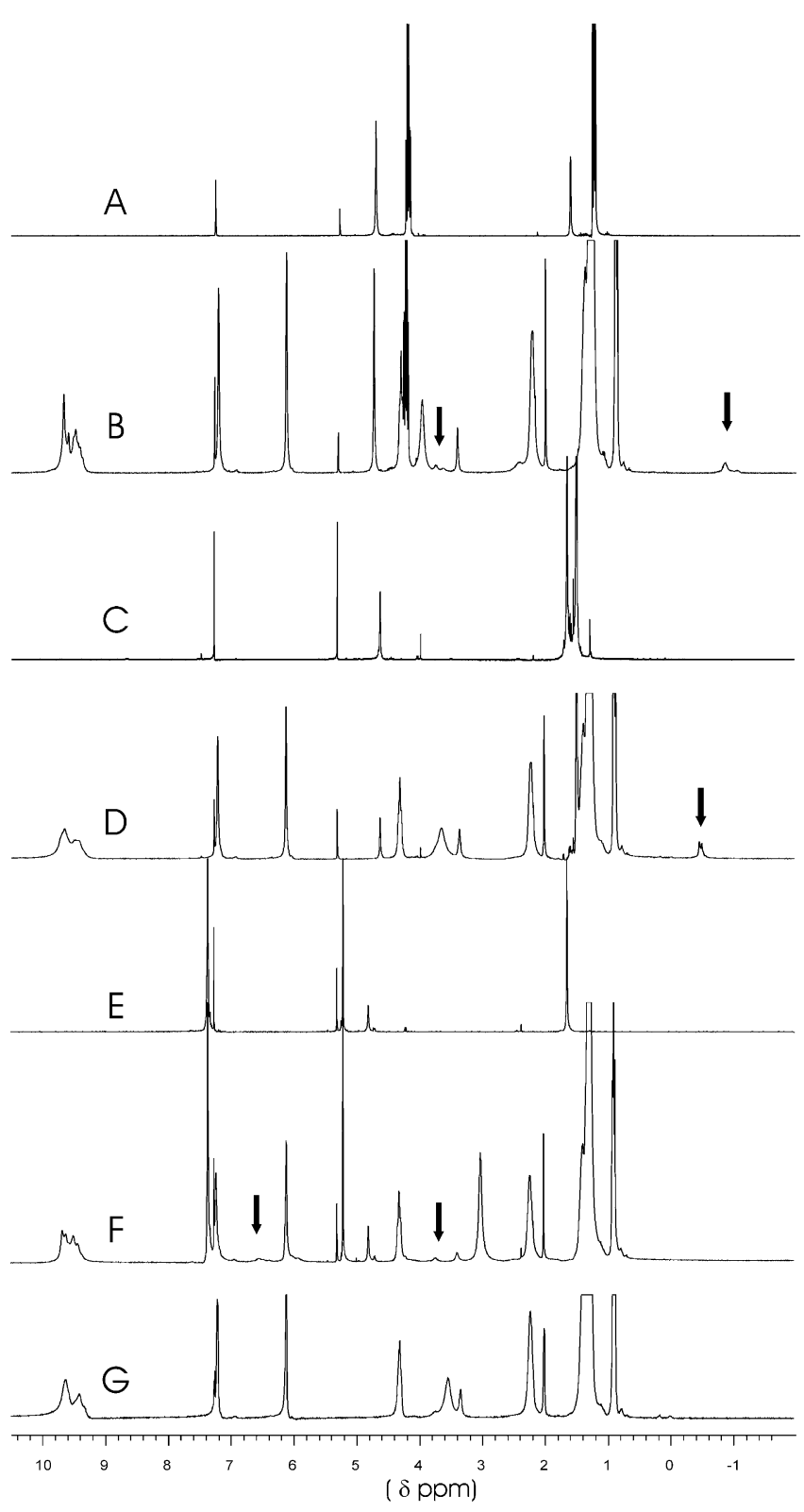

Figure 1. ${ }^{1} \mathrm{H}$ NMR spectra in water-saturated $\mathrm{CDCl}_{3}$ : A) ethyl diazoacetate $(\mathbf{2} \mathrm{a}, 60 \mathrm{~mm}), \mathrm{B}) \mathbf{2} \mathrm{a}(60 \mathrm{~mm})$ and $1(36 \mathrm{~mm}), \mathrm{C})$ tert-butyl diazoacetate $(\mathbf{2} \mathbf{b}$, $60 \mathrm{~mm}), \mathrm{D}) \mathbf{2 b}(60 \mathrm{~mm})$ and $1(36 \mathrm{~mm})$, E) benzyl diazoacetate $(2 \mathrm{c}, 60 \mathrm{~mm})$, F) $2 \mathrm{c}(60 \mathrm{~mm})$ and $1(36 \mathrm{~mm})$, and g) $1(36 \mathrm{~mm})$. $\downarrow$ : encapsulated substrate 1 a-c. Diazoacetate esters 2 a-c contained a small amount (5-15\%) of $\mathrm{CH}_{2} \mathrm{Cl}_{2}$ as a stabilizer.

and maleate esters. ${ }^{[22]} 2 \mathrm{D}$ NMR experiments confirmed the interaction between $\mathbf{2} \mathbf{b}$ and the capsule (see the Supporting Information). DOSY experiments ${ }^{[23]}$ showed a drastic decrease in the diffusion coefficient for the resonances of $\mathbf{2} \mathbf{b}$ once encapsulated (signal at $\delta \approx-0.5 \mathrm{ppm}$ ) that were aligned with those of the capsule. The NOESY experiment showed cross-peaks between the tert-butyl moiety of diazoacetate substrate $\mathbf{2} \mathbf{b}$ and the aromatic $\mathrm{CH}$ group between the two hydroxyl groups of 1 at $\delta=6.1$ ppm. Conversely, neither acrolein (3a) nor methyl acrylate (3e) provided evidence for encapsulation within $\mathbf{1}_{6} \cdot 8 \mathrm{H}_{2} \mathrm{O}$ either in the presence or in the absence of $\mathbf{2} \mathbf{a}$ (see the Supporting Information).
Dipolar cycloaddition reaction between diazoacetate esters $2 \mathrm{a}-\mathrm{c}$ and electron-poor alkenes $3 \mathrm{a}-\mathrm{f}$ promoted by $1_{6} \cdot 8 \mathrm{H}_{2} \mathrm{O}$

Among several different bimolecular reactions, cycloaddition reactions and in particular Diels-Alder reactions represent a benchmark test to investigate the effect of nanoenvironments in catalysis. Cycloaddition reactions have been extensively investigated in both water and organic media by using a wide range of supramolecular unimolecular or self-assembled hosts ranging from cyclodextrins, ${ }^{[24]}$ cucurbiturils, and cavitands to capsules. ${ }^{[25-28]}$ Only one example of a Diels-Alder reaction within a hydrogen-bonded self-assembled capsule such as $1_{6} \cdot 8 \mathrm{H}_{2} \mathrm{O}$ has been reported thus far on the basis of a resorci$\mathrm{n}[4]$ arene bearing fluorous feet operating in a fluorous biphasic system that enabled simple catalyst recycling by decantation. ${ }^{[29]}$ In the latter case, the effect of the capsule could be ascribed to the fluorophobic effect imparted by the solvent that forces the organic substrates to be encapsulated within the cavity; this results in an increased local concentration that promotes the cycloaddition reaction.

Diazoacetate compounds are known to take part in atom-efficient 1,3-dipolar cycloaddition reactions with a wide range of dipolarophiles. ${ }^{[30]}$ The reaction is spontaneous at very high concentrations and alternatively can be catalyzed by Lewis acids and bases as well as by Brønsted acids initially to provide 4,5dihydro-3H-pyrazoles as unstable intermediate species that tautomerize to the corresponding 4,5-dihydro- $1 \mathrm{H}$-pyrazole isomers. ${ }^{[31-33]}$ The stability of such products is highly dependent on the alkene used. It is known that decomposition can be spontaneous or promoted by acids or bases ${ }^{[34]}$ with dinitrogen loss, and this leads to the corresponding cyclopropyl derivatives (Scheme 2). Stable 4,5-dihydro-1H-pyrazoles are prepared by acid catalysis with $\alpha, \beta$-unsaturated aldehydes and ethyl diazoacetate $^{[35]}$ or with metal Lewis acids with other electron-deficient alkenes. ${ }^{[36]}$ Alternatively, they can be synthesized under Baylis-Hillman conditions with Lewis acid and/or Lewis base catalyzed $[3+2]$ cycloaddition reactions. ${ }^{[37,38]}$ The enantioselective version of the reaction is also known and was applied to $\alpha$ - and $\alpha, \beta$-substituted acrolein derivatives. ${ }^{[39,40]}$

Initially, acrolein ( $\mathbf{3} \mathbf{a})$ was selected as a rather active electron-poor alkene, and its reaction with ethyl diazoacetate ( $2 \mathbf{a})$ was investigated at room temperature (Table 1, entries 1-4). The reaction in $\mathrm{CDCl}_{3}$ was sluggish, and corresponding 4,5-dihydro- $1 \mathrm{H}$-pyrazole 4 aa was formed in only $12 \%$ yield after $20 \mathrm{~h}$. The same reaction in the presence of capsule $\mathbf{1}_{6} \cdot 8 \mathrm{H}_{2} \mathrm{O}$ led to $47 \%$ yield of $4 \mathrm{aa}$, and this is indicative of the positive effect imparted by the capsule. To investigate whether or not the catalytic effect of the capsule was due to encapsulation effects, we repeated the experiments with capsule $\mathbf{1}_{6} \cdot 8 \mathrm{H}_{2} \mathrm{O}$ and added a large excess amount of tetraethylammonium tetrafluoroborate $(5 \mathrm{a})$ to the system as a competitive guest for the cavity (see the Supporting Information). Under these conditions, we observed a marked decrease in the yield of 4 aa down to $8 \%$, which indicated the need of an accessible cavity to promote the reaction. With 5 equivalents of $\mathbf{5} \mathbf{a}$ with respect to the capsule, an average of two molecules of ammonium guest per capsule was determined by ${ }^{1} \mathrm{H}$ NMR spectroscopy, and under 


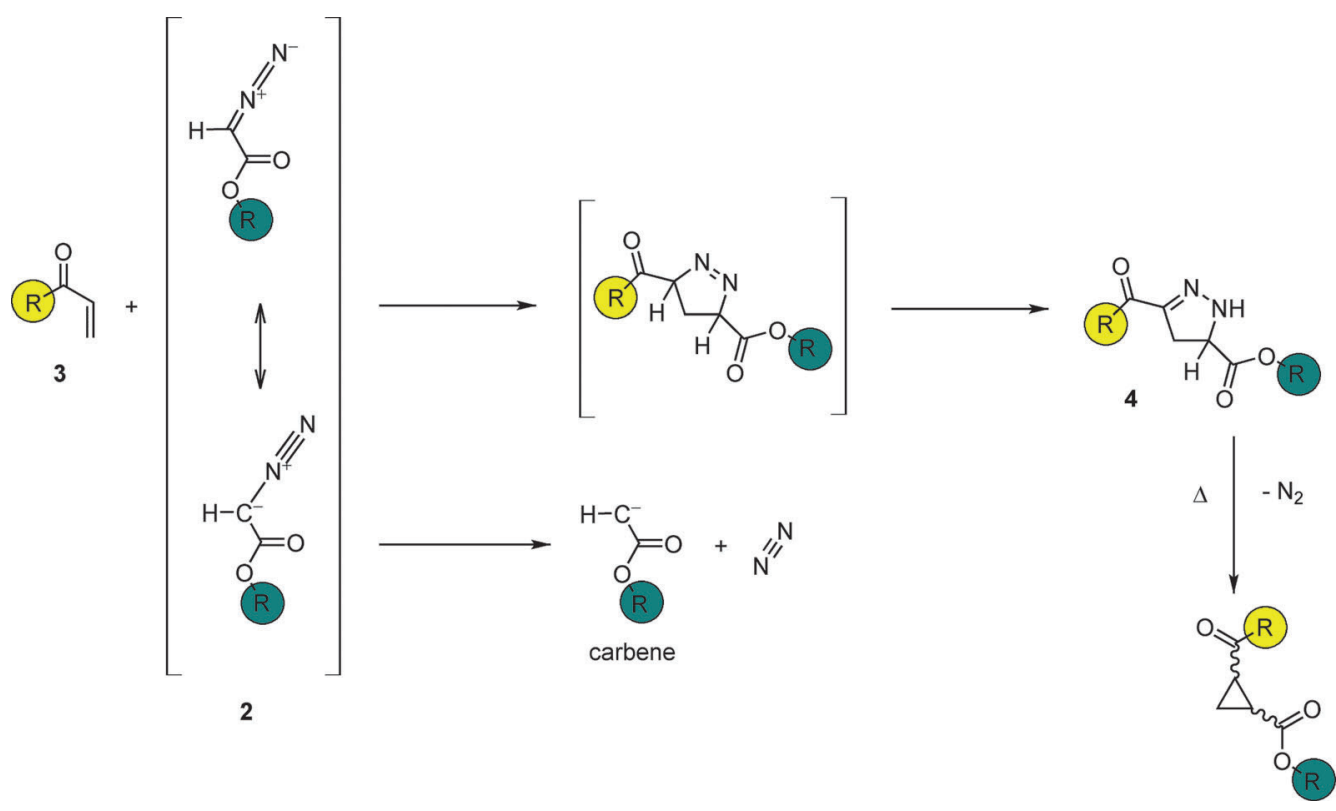

Scheme 2. Reaction between diazoacetate esters 2 and electron-poor alkenes 3 to form 4,5-dihydro-3H-pyrazoles as 1,3-dipolar cycloaddition products that undergo tautomerization to the corresponding more stable 4,5-dihydro- $1 \mathrm{H}$-pyrazoles 4 and in some cases leads to loss of dinitrogen to form the corresponding cyclopropyl derivatives.

Table 1. Catalytic tests for the 1,3-dipolar cycloaddition of diazoacetate esters $2 \mathrm{a}-\mathrm{c}$ with acrolein $(3 \mathrm{a})$ mediated by $\mathbf{1}_{6} \cdot 8 \mathrm{H}_{2} \mathrm{O}$ and control experiments. ${ }^{[\mathrm{a}]}$

\begin{tabular}{|c|c|c|c|c|c|}
\hline Entry & Diazoacetate & $1_{6} \cdot 8 \mathrm{H}_{2} \mathrm{O}$ & $5 a$ & Product & $4[\%]^{[b]}$ \\
\hline 1 & $2 a$ & - & - & 4 aa & 12 \\
\hline 2 & $2 a$ & + & - & 4 aa & 47 \\
\hline 3 & $2 a$ & + & + & 4 aа & 8 \\
\hline $4^{[c]}$ & $2 a$ & - & - & 4 aa & 12 \\
\hline 5 & $2 b$ & - & - & 4 ba & 25 \\
\hline 6 & $2 b$ & + & - & $4 \mathrm{ba}$ & 97 \\
\hline 7 & $2 \mathrm{~b}$ & + & + & $4 \mathrm{ba}$ & 6 \\
\hline $8^{[c]}$ & $2 \mathrm{~b}$ & - & - & $4 \mathrm{ba}$ & 30 \\
\hline 9 & $2 c$ & - & - & $4 \mathrm{ca}$ & 18 \\
\hline 10 & $2 c$ & + & - & $4 \mathrm{ca}$ & 54 \\
\hline 11 & $2 c$ & + & + & $4 \mathrm{ca}$ & 5 \\
\hline $12^{[\mathrm{c}]}$ & $2 c$ & - & - & $4 \mathrm{ca}$ & 29 \\
\hline
\end{tabular}

[a] [1] $=36 \mathrm{~mm},[2 \mathrm{a}-\mathrm{c}]=60 \mathrm{~mm},[3 \mathrm{a}]=60 \mathrm{~mm},[5 \mathrm{a}]=60 \mathrm{~mm}$, water-saturated $\mathrm{CDCl}_{3}(0.5 \mathrm{~mL}), \mathrm{RT}, 20 \mathrm{~h}$. + : present; - : absent. [b] Determined by integration of the signals in the ${ }^{1} \mathrm{H}$ NMR spectrum. [b] [Resorcinol] $=$ $144 \mathrm{~mm}$ (24 equiv. with respect to 1 ).

these conditions, 4 aa was obtained in $10 \%$ yield. With only 1 equivalent of $\mathbf{5} \mathbf{a}$ with respect to the capsule, an average of 0.7 molecules of ammonium inhibitor was encapsulated, which led to $28 \%$ yield of 4 aa. Notably, the reaction between diazoacetates $\mathbf{2} \mathbf{a}-\mathbf{c}$ and $\mathbf{3 a}$ in the presence of ammonium salt $\mathbf{5 a}$ without the capsule led to the formation of the corresponding cycloaddition products in yields of 32,40 , and $20 \%$ for 4 aa, $\mathbf{4} \mathrm{ba}$, and $\mathbf{4} \mathrm{ca}$, respectively. This indicated that the cycloaddition reaction was actually favored by the presence of ammonium species. The experimental observation is in agreement with studies describing the favorable effect of imidazoliumbased ionic liquids ${ }^{[41]}$ in the Diels-Alder reaction between $c y-$ clopentadiene and electron-poor alkenes such as $\mathbf{3} \mathbf{a}$. The acti- vation of the reaction in that case is ascribable to interactions of the dienophile with the imidazolium species. The observation that $\mathbf{5}$ a alone favors the reaction, whereas it is much less active in the presence of capsule $\mathbf{1}_{6} \cdot 8 \mathrm{H}_{2} \mathrm{O}$, could be explained by considering that in the latter case, part of $\mathbf{5 a}$ is trapped within the cavity, whereas the remaining part does not promote the reaction because of possible interactions with the external surface of the capsule.

Moreover, to ascertain the possible activation of the reaction by means of hydrogen bonding, the same reaction was repeated in the presence of 24 equivalents of resorcinol as an $\mathrm{H}$ bonding analogue of $\mathbf{1}_{6} \cdot 8 \mathrm{H}_{2} \mathrm{O}$, and under these conditions, 4 aa was formed in $12 \%$ yield (Table 1 , entry 4 ). This clearly indicates that, even if it is known that the reaction is sensitive to hydrogen bonding, ${ }^{[35]}$ the activation is fully displayed only in the presence of the supramolecular hexamer operating as a single entity.

We then extended the reaction of acrolein to diazoacetate esters $\mathbf{2} \mathbf{b}$ and $\mathbf{2} \mathbf{c}$, and we observed similar effects: 1 ) a marked increase in catalytic activity moving from the uncatalyzed reaction to the reaction performed in the presence of $1_{6} \cdot 8 \mathrm{H}_{2} \mathrm{O}$ (Table 1, entries 5 and 6 and 9 and 10);2) a marked decrease in the yield of the corresponding 4,5-dihydro- $1 \mathrm{H}$-pyrazoles (Table 1, entries 6 and 7 and 10 and 11) if the cavity was occupied by $\mathbf{5} \mathbf{a} ; 3$ ) the insufficient ability of free resorcinol to act as a catalyst (Table 1, entries 8 and 12). Overall, these observations support the idea that the dipolar cycloaddition reaction occurs within the cavity.

Given that the reaction is rather sensitive to the combination of substrates, we further extended the screening of the reaction of tert-butyl diazoacetate ( $\mathbf{2} \mathbf{b}$ ) to other electron-poor alkenes such as acrylonitrile ( $\mathbf{3} \mathbf{b})$, predominantly trans-crotonaldehyde (3c), and trans-2-hexenal ( $3 \mathbf{d}$, Table 2$)$. In all cases, the 


\begin{tabular}{|c|c|c|c|c|c|c|}
\hline Entry & Alkene & $t[\mathrm{~h}]$ & $1_{6} \cdot 8 \mathrm{H}_{2} \mathrm{O}$ & $5 a$ & Product & Yield $[\%]^{[b]}$ \\
\hline 1 & $3 b$ & 20 & - & - & $4 \mathrm{bb}$ & 44 \\
\hline 2 & $3 b$ & 20 & + & - & $4 \mathrm{bb}$ & 58 \\
\hline 3 & $3 b$ & 20 & + & + & $4 \mathrm{bb}$ & 9 \\
\hline 4 & $3 c$ & 48 & - & - & $4 \mathrm{bc}$ & $0^{[c]}$ \\
\hline 5 & $3 c$ & 48 & + & - & $4 \mathrm{bc}$ & 95 \\
\hline 6 & $3 c$ & 48 & + & + & 4 bc & 0 \\
\hline 7 & $3 d$ & 48 & - & - & $4 \mathrm{bd}$ & $0^{[c]}$ \\
\hline 8 & $3 d$ & 48 & + & - & $4 \mathrm{bd}$ & 79 \\
\hline 9 & $3 d$ & 48 & + & + & $4 \mathrm{bd}$ & 0 \\
\hline 10 & $3 e$ & 48 & - & - & 4 be & $1^{[c]}$ \\
\hline 11 & $3 e$ & 48 & + & - & 4 be & 79 \\
\hline 12 & $3 e$ & 48 & + & + & 4 be & 0 \\
\hline 13 & $3 \mathrm{f}$ & 48 & - & - & $4 \mathrm{bf}$ & $2^{[c]}$ \\
\hline 14 & $3 \mathrm{f}$ & 48 & + & - & $4 \mathrm{bf}$ & 18 \\
\hline 15 & $3 \mathrm{f}$ & 48 & + & + & $4 \mathrm{bf}$ & 5 \\
\hline 16 & $3 g$ & 20 & - & - & $4 \mathrm{bg}$ & 30 \\
\hline 17 & $3 g$ & 20 & + & - & $4 \mathrm{bg}$ & 22 \\
\hline
\end{tabular}

[a] [1] $=36 \mathrm{~mm},[\mathbf{2} \mathbf{b}]=60 \mathrm{~mm},[\mathbf{3} \mathbf{b}-\mathbf{h}]=60 \mathrm{~mm},[5 \mathbf{a}]=60 \mathrm{~mm}$, water-saturated $\mathrm{CDCl}_{3}(0.5 \mathrm{~mL}), 50^{\circ} \mathrm{C}$. + : present; - : absent. [a] Determined by integration of the signals in the ${ }^{1} \mathrm{H}$ NMR spectrum. [b] Decomposition products were detected, but the formation of the desired 4,5-dihydro-1H-pyrazole was not observed.

reactions were performed at $50^{\circ} \mathrm{C}$ because of the intrinsic lower reactivity of the alkenes. ${ }^{[42]}$

The reaction with acrylonitrile $(\mathbf{3} \mathbf{b})$ and diazoacetate $\mathbf{2} \mathbf{b}$ led to expected 4,5-dihydro- $1 \mathrm{H}$-pyrazole $\mathbf{4}$ bb with only a slight increase in yield relative to that obtained in the reaction with and without capsule $\mathbf{1}_{6} \cdot 8 \mathrm{H}_{2} \mathrm{O}$, whereas ammonium competitive guest $\mathbf{5}$ a significantly slowed down the reaction (Table 2 , entries $1-3)$. With $\alpha, \beta$-unsaturated aldehydes such as $\mathbf{3} \mathbf{c}$ and $\mathbf{3} \mathbf{d}$, the reaction was slower than that with $\mathbf{3} \mathbf{b}$. In both cases, no reaction was observed without the capsule or with ammonium 5 a as a competitive guest (Table 2, entries 4-6 and 7-9), whereas with the capsule yields of 95 and $79 \%$ for 4 bc and $4 \mathrm{bd}$, respectively, were observed after $48 \mathrm{~h}$ at $50^{\circ} \mathrm{C}$. The study was further extended to other classes of electron-poor alkenes and alkynes such as acrylate esters $\mathbf{3} e$ and $\mathbf{3} \mathbf{f}$ and propiolate ester $\mathbf{3} \mathbf{g}$. With methyl acrylate (3e), decomposition products were observed (Table 2, entry 10 ), whereas with $\mathbf{1}_{6} \cdot 8 \mathrm{H}_{2} \mathrm{O}$, a much cleaner and efficient reaction was observed that led exclusively to 4,5 -dihydro- $1 \mathrm{H}$-pyrazole product $\mathbf{4}$ be in $79 \%$ yield after $48 \mathrm{~h}$ (Table 2 , entry 11 ). Moving to longer acrylate ester $\mathbf{3} \mathbf{f}$, it was evident that the reaction without the capsule was still not efficient, whereas in the presence of the capsule the catalytic effect was much smaller, and the expected product was provided in only $18 \%$ yield. In the latter reactions, a certain degree of substrate selectivity was observed; in fact, the higher yield observed with the shorter acrylate ester is probably not due to electronic effects but can be likely ascribed to better packing of such a smaller substrate with $\mathbf{3} \mathbf{b}$.

It is in fact known that for the encapsulation phenomena good binding is observed if all guests in the cavity occupy no more than $55 \%$ of the available volume, which results in a packing coefficient of 0.55 , typical for most solvents. ${ }^{[6]}$ In the present case, it is evident that all capsules do not have exactly the same composition of the encapsulated guests and that, as a result of the large cavity, some solvent molecules are co-encapsulated with the reagents.

Upon extending the substrate screening to methyl propiolate $(\mathbf{3} \mathbf{g})$, the reaction without the capsule led to the formation of the corresponding $1 \mathrm{H}$-pyrazole in $30 \%$ yield compared to only $22 \%$ yield in the presence of the capsule (Table 2 , entries 16 and 17). This is indicative of the higher intrinsic reactivity of this alkene towards diazoacetates, and in this case, the presence of capsule $1_{6} \cdot 8 \mathrm{H}_{2} \mathrm{O}$ causes inhibition of the reaction.

\section{Conclusions}

We presented an example of the spontaneous encapsulation of diazoacetate esters within self-assembled hexameric capsule $\mathbf{1}_{6} \cdot 8 \mathrm{H}_{2} \mathrm{O}$ driven by the carbene-like character of this class of compounds. In the presence of proper electron-poor alkenes such as acrolein, acrylonitrile, $\alpha, \beta$-unsaturated aldehydes, and acrylate esters, the diazoacetate esters reacted within the cavity of the capsule to form the corresponding cycloadduct 4,5-dihydro- $1 \mathrm{H}$-pyrazoles. The supramolecular catalysis observed was a direct consequence of the encapsulation of the diazoacetate substrates and was ascribed to a combination of weak interactions, difficult to singularly determine, between the substrates and the internal electron-rich surface of the resorcin[4]arene moieties. The acceleration of the reaction was inhibited by the presence of tetraethylammonium tetrafluoroborate, which acted as a competitive guest for the capsule. The confined space of the cavity enabled a significant degree of substrate selectivity in the cycloaddition reaction between the diazoacetate esters and acrylate esters with different alkyl chain; thus, shorter substrates of the series were favored.

\section{Experimental Section}

\section{General}

${ }^{1} \mathrm{H}$ NMR spectra were recorded at $298 \mathrm{~K}$ with a Bruker Avance spectrometer operating at $300.15 \mathrm{MHz}$. GC analysis were performed with an HP Series II 5890 equipped with an HP5 column (30 m, I.D. $0.25 \mathrm{~mm}$, film $0.25 \mu \mathrm{m}$ ) by using $\mathrm{He}$ as the carrier gas and a flame ionization detector. GC-MS analyses were performed with a GC Trace GC 2000 equipped with a HP5 MS column (30 m, I.D. $0.25 \mathrm{~mm}$, film $0.25 \mu \mathrm{m}$ ) by using $\mathrm{He}$ as the gas carrier and coupled with a quadrupole MS Thermo Finnigan Trace MS with the full scan method. Solvents and reactants were used as received; otherwise, they were purified as reported in the literature. ${ }^{[43]}$ TLC analyses were performed on TLC Polygram Sil G/UV254 of $0.25 \mathrm{~mm}$ thickness, and flash chromatography separations were performed on silica gel Merck 60, 230-400 mesh. ${ }^{[44]}$

\section{1,3-dipolar cycloaddition reaction mediated by $\mathbf{1}_{6} \cdot \mathbf{8} \mathrm{H}_{2} \mathrm{O}$}

Typical procedure: A $1.5 \mathrm{~mL}$ vial was charged with a water-saturated chloroform solution of 1 ( $36 \mathrm{~mm}, 0.5 \mathrm{~mL}$ ) followed by diazoacetate ester $2 \mathrm{a}-\mathrm{c}$ (10 equiv. with respect to $1_{6} \cdot 8 \mathrm{H}_{2} \mathrm{O}, 60 \mathrm{~mm}$ ), and the resulting mixture was vigorously stirred until it was completely homogeneous. Subsequently, electron-poor alkene $\mathbf{3} \mathbf{a}-\mathbf{f}$ was added 
(10 equiv. with respect to $\mathbf{1}_{6} \cdot 8 \mathrm{H}_{2} \mathrm{O}, 60 \mathrm{~mm}$ ), and the vial sealed and thermostated at room temperature or at $50^{\circ} \mathrm{C}$. The reaction progress was followed by GC or ${ }^{1} \mathrm{H}$ NMR spectroscopy by sampling the mixture at different times and diluting the sample with water-saturated chloroform. The cycloaddition products were confirmed by GC-MS and ${ }^{1} \mathrm{H}$ NMR spectroscopy. GC-MS analyses demonstrated that 4,5-dihydro- $1 H$-pyrazole derivatives 4 were partially thermally labile, as in several cases significant amounts of the corresponding cyclopropyl products obtained by dinitrogen loss from the 4,5-dihydro- $1 \mathrm{H}$-pyrazole moiety was observed. Nevertheless, no evidence was found for the formation of such cyclopropyl derivatives in solution.

\section{Acknowledgements}

The authors acknowledge the Italian Ministry of Education, University and Research (MIUR) and Università Ca' Foscari di Venezia for financial support.

Keywords: cycloaddition - encapsulation - macrocycles organocatalysis $\cdot$ resorcinarene hexamers

[1] Z. Dong, Q. Luo, J. Liu, Chem. Soc. Rev. 2012, 41, 7890-7908.

[2] U. H. Brinker, J.-L. Mieusset, Molecular Encapsulation: Organic Reactions in Constrained Systems, John Wiley \& Sons, Chichester, 2011.

[3] G. Borsato, J. Rebek, Jr., A. Scarso in Selective Nanocatalysts and Nanoscience: Concepts for Heterogeneous and Homogeneous Catalysis (Eds.: A Zecchina, S. Bordiga, E. Groppo), Wiley-VCH, Weinheim, 2011, pp. $105-$ 168.

[4] a) R. Gramage-Doria, D. Armspach, D. Matt, Coord. Chem. Rev. 2013, 257, 776-816; b) H. J. Schneider, A. K. Yatsimirsky, Chem. Soc. Rev. 2008, 37 263-277; c) H. J. Schneider, Acc. Chem. Res. 2013, 46, 1010-1019; d) J. Wang, S. G. Bodige, W. H. Watson, C. D. Gutsche, J. Org. Chem. 2000, 65 8260-8263; e) G. V. Oshovsky, D. N. Reinhoudt, W. Verboom, Angew. Chem. Int. Ed. 2007, 46, 2366-2393; Angew. Chem. 2007, 119, 2418 2445.

[5] a) M. Raynal, P. Ballester, A. Vidal-Ferran, P. W. N. M. van Leeuwen, Chem. Soc. Rev. 2014, 43, 1660-1733; b) M. Raynal, P. Ballester, A. Vidal-Ferran, P. W. N. M. van Leeuwen, Chem. Soc. Rev. 2014, 43, 1734- 1787.

[6] S. Mecozzi, J. Rebek, Jr., Chem. Eur. J. 1998, 4, 1016-1021.

[7] L. R. MacGillivray, J. L. Atwood, Nature 1997, 389, 469-472.

[8] a) L. Avram, Y. Cohen, J. Am. Chem. Soc. 2002, 124, 15148-15149, b) E. S. Barrett, T. J. Dale, J. Rebek, Jr., J. Am. Chem. Soc. 2008, 130, 2344-2350; c) L. Avram, Y. Cohen, Org. Lett. 2002, 4, 4365-4368; d) L. Avram, Y. Cohen, J. Rebek, Chem. Commun. 2011, 47, 5368-5375 e) B. W. Purse, Proc. Natl. Acad. Sci. USA 2006, 103, 2530-2534; f) A. Shivanyuk, J. Rebek, J. Am. Chem. Soc. 2003, 125, 3432-3433; g) M. Yamanaka, A. Shivanyuk, J. Rebek, J. Am. Chem. Soc. 2004, 126, 2939-2943.

[9] a) L. Avram, Y. Cohen, Org. Lett. 2008, 10, 1505-1508; b) A. Shivanyuk J. Rebek, Jr., Proc. Natl. Acad. Sci. USA 2001, 98, 7662-7665.

[10] I. E. Philip, A. E. Kaifer, J. Am. Chem. Soc. 2002, 124, 12678-12679.

[11] D. A. Dougherty, Acc. Chem. Res. 2013, 46, 885-893.

[12] a) Y. Aoyama, Y. Tanaka, Y. H. Toi, H. Ogoshi, J. Am. Chem. Soc. 1988, 110, 634-635; b) Y. Aoyama, Y. Nonaka, Y. Tanaka, H. Toi, H. Ogoshi, J. Chem Soc. Perkin Trans. 2 1989, 1025-1029.

[13] a) S. Slovak, Y. Cohen, Chem. Eur. J. 2012, 18, 8515-8520; b) S. Slovak, L. Avram, Y. Cohen, Angew. Chem. Int. Ed. 2010, 49, 428-431; Angew. Chem. 2010, 122, 438-441; c) B. Schnatwinkel, I. Stoll, A. Mix, M. V. Rekharsky, V. V. Borovkov, Y. Inoue, J. Mattay, Chem. Commun. 2008, $3873-$ 3875; d) O. Ugono, K. Travis Holman, Chem. Commun. 2006, $2144-$ 2146.
[14] G. Bianchini, A. Scarso, G. La Sorella, G. Strukul, Chem. Commun. 2012, $48,12082-12084$

[15] A. Cavarzan, A. Scarso, P. Sgarbossa, G. Strukul, J. N. H. Reek, J. Am. Chem. Soc. 2011, 133, 2848-2851.

[16] A. Cavarzan, J. N. H. Reek, F. Trentin, A. Scarso, G. Strukul, Catal. Sci. Technol. 2013, 3, 2898-2901.

[17] Q. Zhang, K. Tiefenbacher, J. Am. Chem. Soc. 2013, 135, 16213-16219.

[18] G. Bianchini, G. La Sorella, N. Canever, A. Scarso, G. Strukul, Chem. Commun. 2013, 49, 5322-5324.

[19] R. Ramozzi, N. Chéron, B. Braida, P. C. Hiberty, P. Fleurat-Lessard, New J. Chem. 2012, 36, 1137-1140.

[20] A. Padwa, K. E. Krumpe, Tetrahedron 1992, 48, 5385- 5453.

[21] G. Maas, Angew. Chem. Int. Ed. 2009, 48, 8186-8195; Angew. Chem. 2009, 121, 8332-8341.

[22] J. D. Clark, A. S. Shah, J. C. Peterson, L. Patelis, R. J. A Kersten, A. H. Heemskerk, M. Grogan, S. Camden, Thermochim. Acta 2002, 386, 65-72.

[23] Y. Cohen, L. Avram, L. Frish, Angew. Chem. Int. Ed. 2005, 44, 520-554; Angew. Chem. 2005, 117, 524-560.

[24] J. Yao, Z. Yan, J. Ji, W. Wu, C. Yang, M. Nishijima, G. Fukuhara, T. Mori, Y. Inoue, J. Am. Chem. Soc. 2014, 136, 6916-6919.

[25] Y. Inokuma, S. Yoshioka, M. Fujita, Angew. Chem. Int. Ed. 2010, 49, 8912 8914; Angew. Chem. 2010, 122, 9096-9098.

[26] M. M. J. Smulders, J. R. Nitschke, Chem. Sci. 2012, 3, 785-788.

[27] J. Kang, J. Rebek, Jr., Nature 1997, 385, 50-52.

[28] J. Kang, J. Santamaría, G. Hilmersson, J. Rebek, Jr., J. Am. Chem. Soc. 1998, 120, 7389-7390.

[29] S. Shimizu, A. Usui, M. Sugai, Y. Suematsu, S. Shirakawa, H. Ichikawa, Eur. J. Org. Chem. 2013, 4734-4737.

[30] a) M. Regitz, H. Heydt in 1,3-Dipolar Cycloaddition Chemistry (Ed.: A Padwa), John Wiley \& Sons, New York, 1984, pp. 393-558; b) G. Maas in Synthetic Applications of 1,3-Dipolar Cycloaddition Chemistry toward Heterocycles and Natural Products (Eds.: A. Padwa, W. Pearson), John Wiley \& Sons, New York, 2002, pp. 539-621.

[31] Diazoalkanes with trans-diethyl glutaconate: M. Di, K. S. Rein, Tetrahedron Lett. 2004, 45, 4703-4705.

[32] A. F. Noels, J. N. Braham, A. J. Hubert, Ph. Teyssié, Tetrahedron 1978, 34 $3495-3497$

[33] A. Lévai, Chemistry of Heterocyclic Compounds, 1997, 33, 647-659.

[34] Basic conversion of 4,5-dihydro- $1 \mathrm{H}$-pyrazoles to cyclopropanes: W. M. Jones, P. O. Sanderfer, D. G. Baarda, J. Org. Chem. 1967, 32, 1367-1372.

[35] B. Branstetter, M. Mahmun Hossain, Tetrahedron Lett. 2006, 47, 221 223.

[36] R. A. Novikov, D. N. Platonov, V. A. Dokichev, Yu. V. Tomilov, O. M. Nefedov, Russ. Chem. Bull. 2010, 59, 984-990.

[37] P. Radha Krishna, E. Raja Sekhar, F. Mongin, Tetrahedron Lett. 2008, 49, 6768-6772

[38] P. Radha Krishna, Y. L. Prapurna, Tetrahedron Lett. 2010, 51, 6507-6510.

[39] L. Gao, G.-S. Hwang, M. Young Lee, D. Hyun Ryu, Chem. Commun. 2009 $5460-5462$

[40] T. Kano, T. Hashimoto, K. Maruoka, J. Am. Chem. Soc. 2006, 128, $2174-$ 2175 .

[41] a) R. Bini, C. Chiappe, V. L. Mestre, C. S. Pomelli, T. Welton, Theor. Chem Acc. 2009, 123, 347-352; b) R. Bini, C. Chiappe, V. L. Mestre, C. S. Pomelli, T. Welton, Org. Biomol. Chem. 2008, 6, 2522-2529.

[42] The reaction with $\mathbf{2} \mathbf{b}$ and methacrolein provided evidence of product formation neither with nor without capsule.

[43] D. D. Perrin, W. L. F. Armarego, Purification of Laboratory Chemicals, 3rd ed., Pergamon Press, Oxford, 1993.

[44] W. C. Still, M. Khan, A. Mitra, J. Org. Chem. 1978, 43, 2923-2925

Received: August 11, 2014

Revised: October 23, 2014

Published online on December 12, 2014 